\title{
POST-PLACENTAL INSERTION OF IUCD IN A TERTIARY CARE CENTRE - ACCEPTANCE AND SAFETY
}

\author{
Nisha $S^{1}$, Sathi M. S2, C. P. Vijayan ${ }^{3}$
}

${ }^{1}$ Senior Resident, Department of Obstetrics and Gynaecology, Government Medical College, Kottayam.

${ }^{2}$ Associate Professor, Department of Obstetrics and Gynaecology, Government Medical College, Kottayam.

${ }^{3}$ Additional Professor, Department of Obstetrics and Gynaecology, Government Medical College, Kottayam.

\section{ABSTRACT}

\section{BACKGROUND AND RATIONALE}

To describe the factors associated with acceptability of immediate post-placental intrauterine contraceptive device (PPIUCD) insertion in women according to their sociodemographic and obstetrics characteristics, and to determine the rates of uterine perforation, expulsion, pelvic infection, lost strings and displacement following PPIUCD insertion among the acceptors. This study will enable to advise the policy makers on strategies to enhance positive factors $\{$ e.g. to establish programs that are dedicated in educating parturients and promote post-partum family planning (PPFP)\} and remove negative factors that influence PPIUCD use (i.e. to adopt policies that dispel the parturient misbelieves), so as to increase contraceptive prevalence and ensure an increase in the PPFP choice of methods.

\section{OBJECTIVES}

To study the acceptance and safety of immediate PPIUCD insertion in women delivering vaginally or by caesarean section in our institution during the study period.

\section{STUDY DESIGN}

Prospective observational study.

\section{METHODOLOGY}

A prospective observational study was conducted from April 2014-December 2014 in Government Medical College, Kottayam. Counselling was given to 200 women during routine antenatal checkup and in early labour about the relevance of family planning, different family planning methods and advantages of PPIUCD. The basic profile of the woman regarding the educational status, obstetric score, socioeconomic status, reasons for the acceptance or rejection of IUCD was recorded. Women who have given informed written consent were offered PPIUCD insertion in the post-placental stage, within ten minutes of expulsion of placenta, following vaginal delivery or following caesarean section. After immediate PPIUCD insertion, women were followed up at 6 weeks and three months.

\section{RESULTS}

200 women were counselled and a total of 49 (24.5\%) accepted PPIUCD insertion. Awareness of the PPIUCD among these women was very poor. Majority of the women had heard about the PPIUCD from the antenatal clinics. Acceptance of the PPIUCD was higher among women with secondary level of education than those with primary level of education. In the present study, acceptance of the PPIUCD was higher among primigravida. Convenient timing of insertion and painless nature of insertion contributed to the major reasons for acceptance. Fear of complications of PPIUCD was the major factor responsible for rejection. The expulsion rate was 6.12\%. The PPIUCD was demonstrably safe and effective.

\section{CONCLUSION}

Post-placental IUCD is an effective, reliable, cost effective and safe method of contraception. It is concluded from this study that it is a feasible and acceptable method of contraception. The feasibility of accepting PPIUCD insertion can increase with antenatal counselling and institutional deliveries. Acceptance is high in primiparous women, where spacing method of contraception is of choice. Although PPIUCD has high expulsion rate, on looking into the current increasing population of India, it is better to give this contraceptive option than leaving a postpartum woman at risk of another pregnancy within short interval.

\section{KEYWORDS}

PPIUCD, CuT, Postpartum Family Planning.

HOW TO CITE THIS ARTICLE: Nisha S, Sathi MS, Vijayan CP. Post-placental insertion of IUCD in a tertiary care centre - Acceptance and safety. J. Evolution Med. Dent. Sci. 2016;5(80):5933-5938, DOI: 10.14260/jemds/2016/1340

\section{INTRODUCTION}

India's population is growing exponentially and currently the Indian population has grown up to 1.2 billion. This growing population is putting immense pressure on the constrained resources which are not growing in pace with this population growth. Family planning program has been in place from 1950s and despite all efforts, it is reported in last District

Financial or Other, Competing Interest: None.

Submission 09-07-2016, Peer Review 11-08-2016,

Acceptance 17-08-2016, Published 04-10-2016.

Corresponding Author:

Dr. Nisha $S$

Ottaplackal House, Athirampuzha PO,

Kottayam, Kerala.

E-mail: shamsudeen@gmail.com

DOI: 10.14260/jemds/2016/1340
Household Survey-3 (DLHS-3) that contraceptive use is only $54 \%$ and out of that $7 \%$ are using less reliable traditional methods. As per this report, utilisation of contraceptives is skewed towards female sterilisation and very few couples are opting for spacing methods, which resulted in high unintended pregnancies, which ultimately increase maternal and infant morbidity and mortality. This unmet need for spacing method is very high in the postpartum period and this is mainly attributed to low level of knowledge and myths and misconceptions for spacing methods, particularly for $\mathrm{Cu}-\mathrm{T}$, in community which resulted in low utilisation and discontinuation of method after sometime. The World Health Organization recently revised guidelines on postpartum and newborn care which includes provision of family planning counselling as a core component of postpartum care. 
Contraceptive counselling has become an integral part of antenatal and postpartum programs.

In India, the 2005-2006 National Family Health Survey (NFHS) reported that $61 \%$ of births were spaced less than three years ${ }^{1}$ and that $22 \%$ of married women had an unmet need for family planning. A subsequent stratified analysis suggested that $65 \%$ of women in the first year postpartum had an unmet need for family planning. ${ }^{2}$ IUCDs are used by only two percent of current users of contraception in India. ${ }^{1}$ Recognising the potential impact of improved family planning program on maternal and child health, the Government of India has committed to expanding the access to family planning as a part of achieving the Millennium Development Goals 4 and 5, related to reduction of child and maternal mortality. In 2005, the Government of India launched the Janani Suraksha Yojana (JSY), a conditional cash transfer scheme, to encourage the use of facilities for care at birth. ${ }^{3}$ Since the inception of JSY, facility based births in the public sector have increased from 700,000 in 2005 to more than 11 million in 2012.4 With increasing numbers of women electing to give birth in health institutions, the Government of India decided to strengthen PPFP and to introduce PPIUCD services in a phased manner. The provision of PPIUCD is being rapidly scaled up in India, with facilities in at least 19 states offering the method in 2013.

Nowadays, PPIUCD has been accepted as a safe and reliable method of contraception. Despite the many advantages of the IUCD as a method of family planning, it generally suffers from unpopularity in India. In India, less than two percent of women use the IUCD as their modern contraceptive method of choice. With this background, the present study was undertaken to assess the factors influencing the acceptance and safety of CuT $380 \mathrm{~A}$, a long term reversible method that can serve as an alternative for sterilisation for many women.

\section{MATERIALS AND METHODS}

Counselling was given to women during antenatal checkup, in early labour about the relevance of family planning, and advantages of PPIUCD. The basic profile of the woman regarding the age, educational status, obstetric score, reasons for the acceptance or rejection of IUCD was recorded. Women who have given informed written consent were offered PPIUCD insertion following their delivery after ensuring that they are appropriate clients for IUCD.

\section{Technique of Insertion}

Insertion of the IUCD during this study was done either through transvaginal route or during caesarean section.

\section{Transvaginal Insertion}

\section{The Technique of Transvaginal Insertion is as follows}

Cervix is visualised by inserting a Sims speculum in the vagina and depressing the posterior wall of the vagina. Cervix is cleaned with antiseptic solution. The anterior lip of the cervix is gently held with the sponge forceps. IUCD is taken out of the pack using Kelly's forceps by no touch technique and inserted gently into the lower uterine cavity without touching vaginal wall. The left hand of the inserter is used to push the uterus transabdominally upwards to reduce the angle between uterus and vagina. The Kelly's forceps is then gently moved up in the uterus holding the IUCD firmly until the resistance of the fundus is reached. The IUCD is then released at the fundus and the Kelly's forceps is carefully removed by sweeping it towards the sidewall of the uterus taking care not to dislodge the inserted device. The cervical os is again examined to confirm the fundal placement of IUCD. Once the device is inserted the standard procedures at vaginal delivery are followed as in other cases and the woman is allowed to rest for some time and reassured regarding the insertion and her followup care as well as the benefits of PPIUCD.

\section{Intracaesarean Insertion}

After the removal of placenta, the IUCD is held between index and middle finger and placed through the uterine incision into the fundus. The thread of the device is placed in the uterine cavity and not pushed into the cervical canal, ensuring that it is not caught in the uterine sutures at closure of the uterine wound.

\section{Follow-up Method}

These women were followed up at 6 weeks and 3 months postpartum for signs of infection, expulsion and other complaints. Ultrasound examination was done in cases where the thread of the device was not visible.

\section{Inclusion Criteria}

Women delivering vaginally or by caesarean section counselled for IUCD insertion in prenatal period or in labour and willing to participate in the study.

\section{Exclusion Criteria}

According to medical eligibility criteria for IUCD by WHO, women having the following conditions were excluded.

- Anaemia (haemoglobin $<10 \mathrm{~g} / \mathrm{dL}$ ).

- Postpartum haemorrhage.

- $\quad$ PROM $>18 \mathrm{hrs}$.

- Distorted uterine cavity.

- Fibroid.

- Congenital malformation of uterus.

- Obstructed labour.

\section{Study Variables}

Age, educational status, occupational status, gravidity, time since last childbirth, method of family planning used prior to present pregnancy, interest in PPIUCD insertion, reasons to prefer PPIUCD, reasons to reject PPIUCD, other preferred forms of contraception, type of PPIUCD, complications.

\section{Statistical Method}

Statistical analysis was performed using SPSS software (Version 22). The values were entered and their statistical significance was analysed using chi-square test. $\mathrm{P}$ value of $<0.05$ was regarded as statistically significant.

\section{OBSERVATIONS AND RESULTS}

A total of 200 women were approached for PPIUCD insertion, 49 (24.5\%) women accepted PPIUCD insertion while almost three quarters of them declined insertion (Table 1). $22.7 \%$ of the women belonging to the age group 20 to 29 years were interested in PPIUCD insertion The interest of the women and their age was found to be significantly associated (Table 2). 38.7\% of women with secondary level education were interested in PPIUCD insertion, while only $12.5 \%$ of women with primary level of education were interested. The interest of the women and their educational level are 
significantly associated as $\mathrm{P}$ value was $<0.05$ (Table 3 ). $71.4 \%$ women interested in PPIUCD insertion had not used any family planning method prior to present pregnancy (Table 4). A significant association was found between the interest in insertion and use of any method of family planning prior to present pregnancy $\left(\mathrm{X}^{2} ; \mathrm{P}<0.05\right)$. Among the 49 cases who underwent PPIUCD insertion, $36(73.46 \%)$ of them had no complaints. Expulsion rate was $6.12 \%, 4.08 \%$ developed infection, while $8.16 \%$ had other complaints like abdominal pain, heavy vaginal bleeding. Two women discontinued the use at 6 weeks due to abdominal pain and heavy menstrual bleeding (Table 5). $79 \%$ of the women had no complaints, while $7 \%$ had other complaints like abdominal pain, heavy menstrual bleeding (Table 6). Convenient timing of insertion (42.85\%) was the main reason behind the acceptance (Graph 1). Fear of complications of IUCD (37\%) was the main factor contributing to the rejection of PPIUCD (Graph 2).

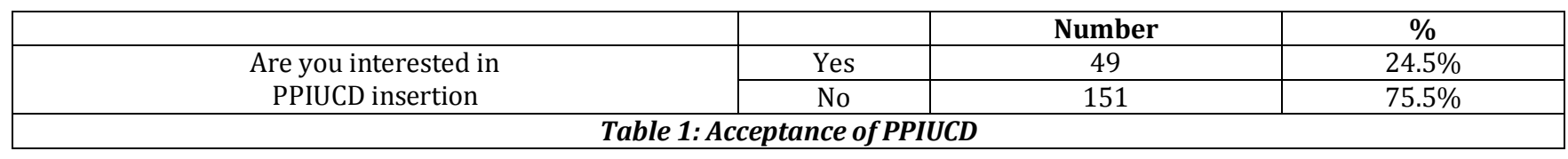

\begin{tabular}{|c|c|c|c|c|c|c|c|c|}
\hline & & & & & Age & & & \\
\hline & & & $\begin{array}{l}19 \text { Years } \\
\text { Below }\end{array}$ & $\begin{array}{c}20 \text { to } 29 \\
\text { Years }\end{array}$ & $\begin{array}{c}30 \text { to } 39 \\
\text { Years }\end{array}$ & Total & $\mathbf{X}^{2}$ & $\begin{array}{c}\text { Significant } \\
\text { Level }\end{array}$ \\
\hline \multirow{4}{*}{$\begin{array}{l}\text { Interested in } \\
\text { PPIUCD }\end{array}$} & \multirow{2}{*}{ Yes } & $\mathrm{N}$ & 6 & 34 & 9 & 49 & \multirow{4}{*}{19.15} & \multirow{4}{*}{$\begin{array}{c}\mathrm{P}<0.05 \\
\text { Level }\end{array}$} \\
\hline & & $\%$ & $100.0 \%$ & $22.7 \%$ & $20.5 \%$ & $24.5 \%$ & & \\
\hline & \multirow{2}{*}{ No } & $\mathrm{N}$ & 0 & 116 & 35 & 151 & & \\
\hline & & $\%$ & $0.0 \%$ & $77.3 \%$ & $79.5 \%$ & $75.5 \%$ & & \\
\hline \multirow{2}{*}{ Total } & & $\mathbf{N}$ & 6 & 150 & 44 & 200 & & \\
\hline & & $\%$ & $100.0 \%$ & $100.0 \%$ & $100.0 \%$ & $100.0 \%$ & & \\
\hline \multicolumn{9}{|c|}{ Table 2: Distribution According to Age } \\
\hline
\end{tabular}

\begin{tabular}{|c|c|c|c|c|c|c|c|c|}
\hline & & & \multicolumn{5}{|c|}{ Educational Qualification } & \multirow[b]{2}{*}{ P Value } \\
\hline & & & \multicolumn{3}{|c|}{ Educational Qualification } & \multirow[t]{2}{*}{ Total } & $\mathbf{X}^{2}$ & \\
\hline \multirow{5}{*}{ Interested in PPIUCD } & \multirow{3}{*}{ Yes } & & Primary & Secondary & College & & \multirow{6}{*}{13.53} & \multirow{7}{*}{$\mathrm{P}<0.05$} \\
\hline & & $\mathrm{N}$ & 6 & 29 & 14 & 49 & & \\
\hline & & $\%$ & $12.5 \%$ & $38.7 \%$ & $18.2 \%$ & $24.5 \%$ & & \\
\hline & \multirow{4}{*}{ No } & $\mathrm{N}$ & 42 & 46 & 63 & 151 & & \\
\hline & & $\%$ & $87.5 \%$ & $61.3 \%$ & $81.8 \%$ & $75.5 \%$ & & \\
\hline \multirow{2}{*}{ Total } & & $\mathbf{N}$ & 48 & 75 & 77 & 200 & & \\
\hline & & $\%$ & $100.0 \%$ & $100.0 \%$ & $100.0 \%$ & $100.0 \%$ & & \\
\hline
\end{tabular}

\begin{tabular}{|c|c|c|c|c|c|c|c|}
\hline & & & \multicolumn{2}{|c|}{ Any Method of Family Planning Prior to Present Pregnancy } & \multirow{2}{*}{ Total } & \multirow{2}{*}{$\mathbf{X}^{2}$} & \multirow{2}{*}{ P value } \\
\hline & & & Yes & No & & & \\
\hline \multirow{4}{*}{ Interested in PPIUCD } & Yec & $\mathrm{N}$ & 15 & 34 & 49 & \multirow{4}{*}{8.84} & \multirow{4}{*}{$\mathrm{P}<0.05$} \\
\hline & Yes & $\%$ & $30.61 \%$ & $71.42 \%$ & $100 \%$ & & \\
\hline & \multirow[b]{2}{*}{ No } & $\mathrm{N}$ & 80 & 71 & 151 & & \\
\hline & & $\%$ & $52.98 \%$ & $47.01 \%$ & $100 \%$ & & \\
\hline \multicolumn{2}{|l|}{ Total } & $\mathbf{N}$ & 95 & 105 & 200 & & \\
\hline & & & $\begin{array}{r}\text { Table 4: Distr } \\
\text { of prio }\end{array}$ & ptance & & & \\
\hline
\end{tabular}

\begin{tabular}{|c|c|c|c|c|c|c|}
\hline & \multicolumn{5}{|c|}{ Six Weeks Follow-Up } & \multirow[b]{2}{*}{ Total } \\
\hline & Expulsion & Infection & $\begin{array}{c}\text { Missing } \\
\text { Strings }\end{array}$ & $\begin{array}{c}\text { Other } \\
\text { Complaints }\end{array}$ & $\begin{array}{c}\text { No } \\
\text { Complaints } \\
\end{array}$ & \\
\hline Number & 3 & 2 & 4 & 4 & 36 & 49 \\
\hline$\%$ & $6.12 \%$ & $4.081 \%$ & $8.16 \%$ & $8.16 \%$ & $73.46 \%$ & $100.0 \%$ \\
\hline
\end{tabular}

\begin{tabular}{|c|c|c|c|c|c|}
\hline & \multicolumn{4}{|c|}{3 Months } & \multirow{2}{*}{ Total } \\
\hline & Infection & Other Complaints & Missing Strings & No Complaints & \\
\hline No. & 2 & 3 & 4 & 35 & 44 \\
\hline$\%$ & $4.65 \%$ & $6.97 \%$ & $9.30 \%$ & $79.54 \%$ & $100.0 \%$ \\
\hline
\end{tabular}




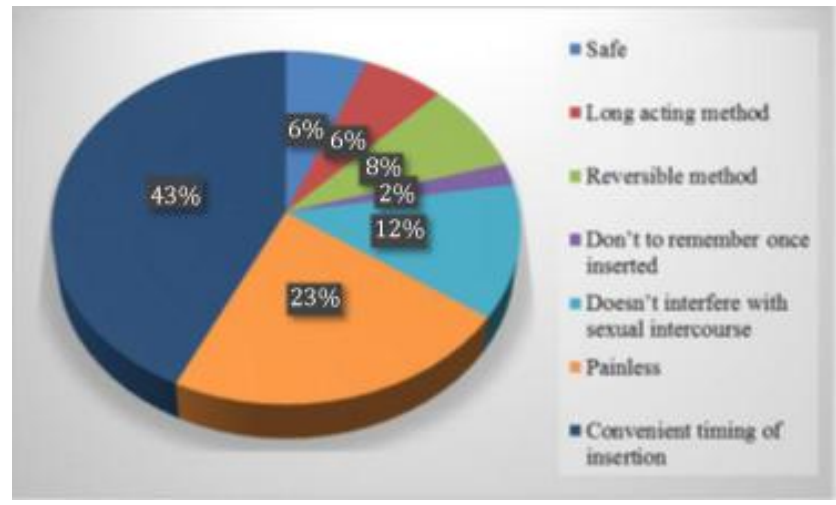

Graph 1: Reasons to Prefer PPIUCD

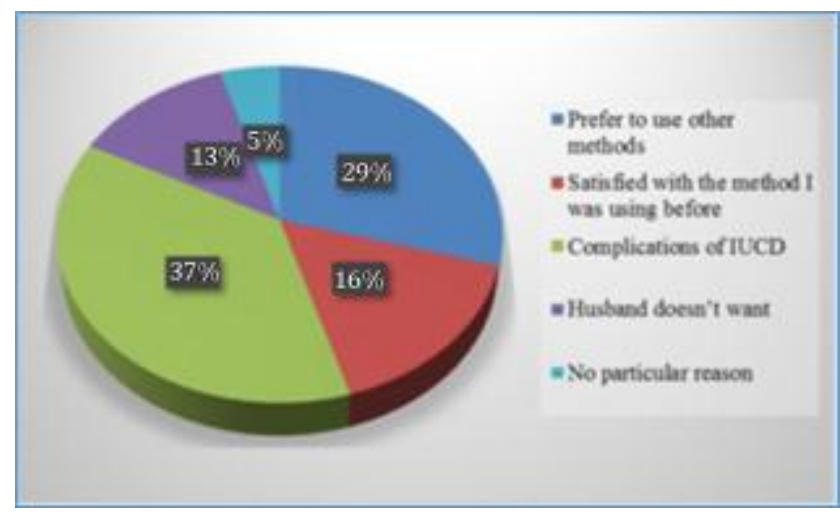

Graph 2: Reasons to Reject PPIUCD

\section{DISCUSSION}

Looking into the exploding population of India, population control and stabilisation is the demand of the nation, for the socioeconomic development and welfare of country. Although the available contraceptive methods are many, need of a single efficacious, feasible, and cost effective method is desirable especially in a low resource country like India. The present study was conducted to assess the acceptability, and complications of IUCD insertion in the immediate postplacental period among women delivering in our setup.

According to UN 1997, TCu380A confers contraceptive protection similar to that achieved with tubal sterilisation. In the present study, 49 (24.5\%) women were willing for PPIUCD insertion, while 151 (75.5\%) women refused PPIUCD insertion, making the acceptance rate $24.5 \%$.

A study done by Mohamed et al showed that making contraceptive methods easy and convenient for women, makes a big difference in ultimate acceptance. In their study, 1024 women were counselled for immediate postpartum insertion of IUCD. Of those who agreed for immediate insertion, $71.2 \%$ had the IUCD inserted. Compared to this study, acceptance rate in our study is low and possible reasons could be lack of awareness, low education, family pressure and various misconceptions for IUCD insertion.

Majority belonged to age group of 20-29 years. In a study by Saroj et al in 2012, majority of women (52\%) belonged to age group 20-25 years. Alvarez Peyalo et al (1996) also found that average age of PPIUCD acceptors was 20.6\%.4 This was because they considered PPIUCD as an effective spacing method. This reflects the national fertility rate data. Since the mean age at marriage in our state remains at 22.7, it points towards the large group of young fertile women who have an unmet need of family planning and should be counselled and offered an effective family planning method.

Acceptance of the PPIUCD was higher among women with secondary level of education than those with primary level of education. This could be reasoned out that educated women are high achievers. This was similar to a study done in Egypt by Safwat et al where women with no formal education had acceptance of $9.4 \%$ while those with formal education was $19.4 \% .^{5}$ Education has a positive effect on modern contraceptive use as shown in a study done in Zimbabwe. It was only apparent among women who completed secondary education (12 years or more). Women who completed secondary school were about twice as likely to use modern contraceptive methods as women who did not complete primary education. ${ }^{6}$ Education renders people more receptive to new ideas and practices, spacing methods, and importance of small family norms. Education is also a major factor in fertility control. Choudhary et al found secondary and higher education influenced contraceptive use. ${ }^{7}$ Ullah and Chakraborty et al showed woman's education as the most important determinant of contraceptive use. ${ }^{8}$

In our study, acceptance of the PPIUCD was lower among grand multiparas compared to primiparous ladies, which was not statistically significant. Study done by Safwat et al in Egypt showed that $30 \%$ of primiparous ladies accepted the use of PPIUCD compared to $15 \%$ of multipara. Advantages of immediate post-partum insertion include high motivation, assurance that the woman is not pregnant, and convenience, Grimes D. ${ }^{9}$

According to Patel and Khan ${ }^{10}$, men approve use of contraceptive only after having $2^{\text {nd }}$ or $3^{\text {rd }}$ child. In a study conducted by Bhalerao AR et al,11 $46.5 \%$ of the women were para- $1,46 \%$ were para- 2 and $69 \%$ had accepted IUDs because they had at least 1 living male child. The duration since the parturient's last child birth was not significantly associated with acceptance of PPIUCD. More than a third of the parturients (26.1\%) who had the PPIUCD inserted, had their last childbirth between 2-3 yrs. This could be explained that women who had a short pregnancy interval to the index pregnancy felt they required a long acting and reliable method of contraception. This also has the added advantage of giving the mother enough time to recover from the physical stress of one pregnancy before moving on to the next and gives enough time for lactation. In a report released by WHO in 2006, healthy timing and spacing of pregnancies has a positive effect on maternal health and newborn outcomes.

This study shows a significant association between the interest in insertion and use of any method of family planning prior to present pregnancy. $71.4 \%$ women who were interested in PPIUCD insertion had not used any family planning method prior to present pregnancy. The common methods of contraception previously used by the study sample were contraceptive pills, condoms, natural methods and lactational amenorrhoea. All were short-term methods.

Among women whom PPIUCD was inserted, $42.5 \%$ accepted due to its convenient timing of insertion, $22.4 \%$ as the insertion was painless and $6 \%$ as the method was long acting. This shows that postpartum women need a contraceptive method which is convenient, safe and long acting.

In the present study, 151 cases who refused post-partum IUCD insertion were interviewed for cause of refusal and also 
their choice for other contraception. 37.3\% declined PPIUCD insertion due to fear of complications of IUCD, 29.3\% preferred to use other methods and $16.0 \%$ were satisfied with previous method. This was consistent with the study of Rajni Gautam et al,12 14\% did not accept any contraception. 57\% had fear of menstrual problems like irregularities and pain. $16 \%$ were satisfied with previous family planning method. $12.7 \%$ patients refused accepting PPIUCD insertion as their husbands were not interested and $4.7 \%$ could not specify the reason. Priya et $\mathrm{al}^{13}$ explored the reasons behind low acceptance of PPIUCD and found that most common reason for low acceptance of PPIUCD was lack of involvement of husbands. A significant number of women declined the PPIUCD because of non-partner involvement. This reveals the importance of partner involvement during counselling and decision making. Many studies have shown that when the partner is involved in contraceptive counselling and decision making, the acceptance and continuation rates were higher. In Africa, postpartum study done by FHI, husband's desire for IUCD removals was a significant reason for removal, emphasising the importance of involving the husband in prenatal counselling. But in a study done in Egypt, among the $71.1 \%$ women who refused the IUCD, planning another pregnancy in the near future (34.3\%) was the most common reason followed by preference of interval IUCD (30.2\%) and lactational amenorrhoea (9.3\%). Complications from previous use of IUCD (9.7\%) or absence of husbands (3.4\%) were some other reasons.

This study found that acceptability of PPIUCD insertion was more following a vaginal delivery (57.15\%) than following a caesarean section (42.85\%). This was in contrast to a study done by Shukla et al $^{14}$ in which the caesarean group (62\%) was more than vaginal delivery group (37\%).

Out of total women who accepted post-placental IUCD insertion, $73.46 \%$ had no complaints. The gross cumulative expulsion rate found in the present study was $6.12 \%$. This was similar to a multicountry study done in Belgium, Chile and Philippines which showed the rate of expulsion at 1 month ranging from $4.6-16.0 \%$. Expulsion rate of immediate PPIUCD in a study done in China by Chi et al 1994 was $25-37 \%$ while post-placental was 9.5 - 12.5\%. Expulsion of PPIUCD usually occurs in the first few months after insertion. No cases of uterine perforation or pregnancy with IUCD in situ were reported during the study.

This is in accordance with the study of El Shafei MM et al (2000) ${ }^{15}$ and Ricalde et al (2006) ${ }^{16}$ where no perforations were observed in PPIUCD. No case reported interference of $\mathrm{Cu}$ T with lactation as also found by Diaz S et al (1993), ${ }^{17}$ Diaz S et al (1997) and Zacharias S et al(1986). ${ }^{18}$ Tatum HJ et al found that the gross cumulative expulsion rate in their study was $16.2 \% .^{19}$ According to Bhalerao et al the expulsion rate was $16.4 \%$. The high incidence was considered due to atrophic or bulky uterus present in some women and due to the fact that only one size IUD was available. Chi IC et al found that there is a lower expulsion rate with immediate post-placental insertion than with immediate postpartum insertion. As well, insertion during caesarean section has a lower expulsion rate than insertion during the postpartum (first 48 hours) period.

This is likely due to the fact that it is easier to reliably reach the uterine fundus during post-placental or caesarean section. When a copper $\mathrm{T}$ device is inserted post-placentally or immediately postpartum by an experienced and trained clinician, the expected expulsion rates could be $7-15 \%$ at six months. In this study, there was no case of expulsion at three months..$^{20}$ In this study, pelvic infection (4.081\%) was slightly high compared to a study done in Kenya and Mali which indicated a rate of less than $2 \%$. A study done in Ethiopia revealed that lower genital tract infections are very common among apparently healthy looking pregnant women with an overall prevalence of $40-54 \% .^{21}$

This higher incidence of untreated reproductive tract infection increases the risk of pelvic infection after immediate PPIUCD insertion. Four women (8.16\%) among those inserted with PPIUCD had lost strings at six weeks. An ultrasound confirmed that the IUCD was in situ. This indicated possible retraction or curling of the strings into the endocervical canal or uterine cavity. Absence of uterine perforation with extremely low rates of expulsion (6.4\%), pelvic infection $(4.08 \%)$ and lost strings $(8.16 \%)$ are strong indicators of safety. However, two women discontinued the use of PPIUCD due to abdominal pain and heavy menstrual bleeding.

\section{CONCLUSION}

Post-placental IUCD is an effective, reliable, cost effective and safe method of contraception. It is concluded from this study that it is a feasible and acceptable method of contraception. The feasibility of accepting PPIUCD insertion can increase with antenatal counselling and institutional deliveries. Acceptance is high in primiparous women, where spacing method of contraception is of choice. Although PPIUCD has high expulsion rate, on looking into the current increasing population of India, it is better to give this contraceptive option than leaving a postpartum women at risk of another pregnancy with in short interval.

\section{ACKNOWLEDGEMENTS}

I am deeply indebted to Dr. C. P. Vijayan, Additional Professor, Department of Obstetrics and Gynaecology, Medical College, Kottayam for his aspiring guidance and, invaluably constructive criticism during this study. I wish to express my sincere thanks to Dr. Sathi. M.S., Associate Professor, Department of Obstetrics and Gynaecology, Medical College, Kottayam for sharing her expertise and sincere and valuable guidance. I owe to my deep sense of gratitude to former and current Professor and HOD, Dr M.A. Kunjamma and Dr T. J. Cicily for her valuable guidance, concern and support throughout the course of this work. I remember with immense gratitude, Mr. Suchithran, Statistician, whose expertise has been used in this work. My heartfelt thanks to all my teachers, staff of Family Planning Department, my colleagues and friends for their cooperation extended throughout this study. I thankfully remember all the patients who trusted me and were central to materialising this study. Words are inadequate regarding my family for their constant support, love and blessings. Finally, I gratefully reckon the providential grace which stood as a powerful source of inspiration and strength at every stage of this study.

\section{REFERENCES}

1. United Nations Development Programme/UN Population Fund/WHO/World Bank, Special Programme of Research, Development and Research Training in human Reproduction. Longterm reversible contraception. Twelve years of experience with the TCu380A and TCu220C. Contraception 1997;56(6):341-52. 
2. Peterson HB, Xia Z, Hughes JM, et al. The risk of pregnancy after tubal sterilization: findings from the U.S. collaborative review of sterilization. Am J Obstet Gynecol 1996;174(4):1161-8.

3. Mohamed SA, Kamelss MA, Shaaban OM, et al. Acceptability for the use of postpartum intrauterine contraceptive devices: Assiut experience. Med Princ Pract 2003;12(3):170-5.

4. Pelayo AJ, Sala BME. IUD Insertion during caesarean section and its most frequent complication. Ginecol Obstet Mex 1994;62:330-5.

5. Thomas D, Maluccio J. Fertility, contraceptive choice, and public policy in Zimbabwe. The World Bank Economic Review 1996;10(1):189-222.

6. Choudhary RH. The influence of female education, labour force participation \& age at marriage on fertility behaviour in Bangladesh. Social Biology 1984;31(1-2):59-74.

7. Ullah MS, Chakraborty N. The use of modern \& traditional methods of fertility control in Bangladesh: a multivariate analysis. Contraception 1994;50(4):363-72.

8. Grimes D, Lopez LM, Schulz KF, et al. Immediate postpartum insertion of intrauterine devices: A Cochrane review. Hum Reprod 2002;17(3):549-54.

9. Khan ME, Patel BC. Male involvement in family planning: a knowledge, attitude, behaviour and practice survey of Agra district. New Delhi: population council 1997.

10. Bhalerao AR, Purandare MC. Post-puerperal Cu-T insertion: a prospective study. J Postgrad Med 1989;35(2):70-3.

11. Gautam R, Arya KN, Kharakwal S, et al. Overview of immediate PPIUCD application in Bundelkhand region. J Evol Med Dent Sci 2014;3(36):9518-26.

12. Priya JHA. Compendium of sessions addressing south Asian health at the 2012 APHA meeting. In: Priya Jha, edr. SAPHA Compendium. India: Compiled by the South Asian Public Health Association 2012:8-7.
13. Shukla M, Qureshi S, Chandrawati. Post placental intrauterine device insertion a five year experience at a tertiary care centre in north India. Indian J Med Res 2012;136(3):432-5.

14. El-Shafei MM, Mashali A, Hassan EO, et al. Postpartum and post abortion intra uterine device insertion unmet needs of safe reproductive health: 3 years experience of a Mansoura University Hospital. Egypt Soc Obstet Gynaecol 2000;26:253-62.

15. Ricalde LR, Tobias MG, Pérez RC, et al. Random comparative study between intrauterine device multiload Cu375 and TCu380A inserted in the postpartum period. Ginecol Obstet Mex 2006;74(6):306-11.

16. Diaz S, Zepeda A, Maturana X, et al. Fertility regulation in nursing women. IX. Contraceptive performance, duration of lactation, infant growth, and bleeding patterns during use of progesterone vaginal rings, progestin only pills, Norplant implants, and copper T 380-a intrauterine devices. Contraception 1997;56(4):223-32.

17. Zacharias S, Aguilera E, Assenzo JR, et al. Effects of hormonal and non-hormonal contraceptives on lactation and incidence of pregnancy. Contraception 1986;33(3):203-13.

18. Tatum HJ, Beltran RS, Ramos R, et al. Immediate postplacental insertion of GYNE-T 380 and GYNE-T 380 postpartum contraceptive devices: randomized study. Am J Obstet Gynecol 1996;175(5):1231-5.

19. Marai W. Lower genital tract infections among pregnant women: a review. East African Medical Journal 2001;78(11):581-5.

20. WHO Improving access to quality care in family planning: Medical Eligibility criteria for contraceptive use. Geneva, World Health Organization 1996.

21. Peri N, Graham D, Levin D. Imaging of intrauterine contraceptive devices. Journal of Ultrasound Med 2007;26(10):1389-401. 